Article

\title{
Thermal-Mechanical Properties of Polyurethane-Clay Shape Memory Polymer Nanocomposites
}

\author{
Bin Xu ${ }^{1}$, Yong Qing Fu ${ }^{1,2, *}$, Wei Min Huang ${ }^{3}$, Yu Tao Pei ${ }^{4}$, Zhen Guo Chen ${ }^{4}$, \\ Jeff T.M. De Hosson ${ }^{4}$, Arno Kraft ${ }^{1}$ and R. L. Reuben ${ }^{1}$
}

1 Department of Mechanical Engineering, School of Engineering and Physical Sciences, Heriot-Watt University, Edinburgh, EH14 4AS, UK; E-Mails: bx13@hw.ac.uk (B.X.); A.Kraft@hw.ac.uk (A.K.); R.L.Reuben@hw.ac.uk (R.L.R.)

2 School of Materials Science and Engineering, Xi'an University of Technology, Xi'an 710048, Shanxi, China

3 School of Mechanical and Aerospace Engineering, Nanyang Technological University, 50 Nanyang Avenue, 639798, Singapore; E-Mail: mwmhuang@ntu.edu.sg

4 Department of Applied Physics, The Netherlands Materials Innovation Institute, University of Groningen, Nijenborgh 4, 9747 AG Groningen, The Netherlands; E-Mails: y.pei@rug.nl (Y.T.P.); Zhenguo.Chen@rug.nl (Z.G.C.); j.t.m.de.hosson@rug.nl (J.T.M.D.H.)

* Author to whom correspondence should be addressed; E-Mail: R.Y.Fu@hw.ac.uk; Tel.: +44-0131-4514381; Fax: +44-0131-4513129.

Received: 15 January 2010; in revised form: 15 April 2010 / Accepted: 22 April 2010 / Published: 26 April 2010

Abstract: Shape memory nanocomposites of polyurethane (PU)-clay were fabricated by melt mixing of PU and nano-clay. Based on nano-indentation and microhardness tests, the strength of the nanocomposites increased dramatically as a function of clay content, which is attributed to the enhanced nanoclay-polymer interactions. Thermal mechanical experiments demonstrated good mechanical and shape memory effects of the nanocomposites. Full shape memory recovery was displayed by both the pure PU and PU-clay nanocomposites.

Keywords: shape memory; nanocomposites; polyurethane; nano-clay; Vickers indentation; microhardness 


\section{Introduction}

Shape-memory polymers (SMPs) have the capability of recovering their shape upon application of external stimuli such as thermal treatment, joule heating, light, or chemicals [1-4]. Compared with shape memory alloys (SMAs), the advantages of SMPs include high elastic deformation and large recoverable strain (up to 400\%), low cost for fabrication and processing, excellent chemical properties, biocompatibility and/or biodegradability [5,6]. Polyurethane (PU) based SMPs are among the most promising low-cost, low-density materials with excellent shape-memory ability and flexibility [7-9]. Their glass transition temperature can be tailored for shape restoration/self-deployment of in a variety of clinical and biological applications. However, one major problem of SMPs for biological applications such as microsurgery, in comparison with other shape-memory materials (alloys and ceramics), is their low recovery force (due to the low stiffness of most SMPs), which severely limits the SMP's ability to recover when faced with large mechanical resistance. To overcome this problem, nanocomposite SMPs have been proposed where a shape-memory polymer matrix is reinforced with nano-sized particles and fillers, which leads to significant improvements in the mechanical properties and other functional properties, such as the shape memory effect $[7,10]$. Different types of nano-fillers (including nano ceramic and metal nanopowders, nano clay, carbon nanotubes and nano-silica, etc.) have been used to reinforce the polymer matrix [11-16]. Attapulgite based nano-clay is a natural hydrated magnesium-aluminium silicate consisting of nano-rods with a diameter of less than $100 \mathrm{~nm}$ and a length ranging from hundreds of nanometres to several micrometres for each single rod [17,18]. Its high aspect ratio and large surface area make it effectively reinforce the polymer matrix [19]. Our previous results showed that heat treated attapulgite nanoclay could significantly enhance mechanical properties of PU shape memory polymer [20]. Heat-treatment of the nano-clay removed the moisture and most surface hydroxyl groups, resulted in a crystallized and bundled structure, improved the interface between polymer and nano-fillers, and enhanced the mechanical properties of the nanocomposites [20]. Detailed studies on microstructure and thermal mechanical performance of the nanocomposites may provide useful guides for their engineering applications. In this paper, the thermal mechanical performance of the PU-clay nanocomposites is described.

\section{Materials and Methods}

PU-MM5520 pellets from Mitsubishi Heavy Industries,Japan, and attapulgite clay were used in this study. The attapulgite clay was heat-treated in an furnace (in air) at $850{ }^{\circ} \mathrm{C}$ for 2 hours [20,21], and then held in an oven at $100{ }^{\circ} \mathrm{C}$ for 12 hours. High resolution transmission electron microscopy (HR-TEM, JEOL 2010F) showed that the treated nano-clay formed a three-dimensional bundled network structure in which the length of single clay fibre varied from sub-micrometer to a few micrometers and the diameter was in the order tens of nanometres (see Figure 1(a)). The ring-like scattered diffraction spots reveal the nanocrystalline feature of the treated fibres as shown by the inset electron diffraction pattern in Figure 1(a). The corresponding HR-TEM images in Figure 1(b,c) confirm that the individual crystallites are embedded in the amorphous matrix with a separation of a few nanometres. 
Figure 1. TEM observation of heat-treated clay powder: (a) Overview and electron diffraction pattern, (b) and (c) HR-TEM micrographs taken at the indicated position of a clay cluster.
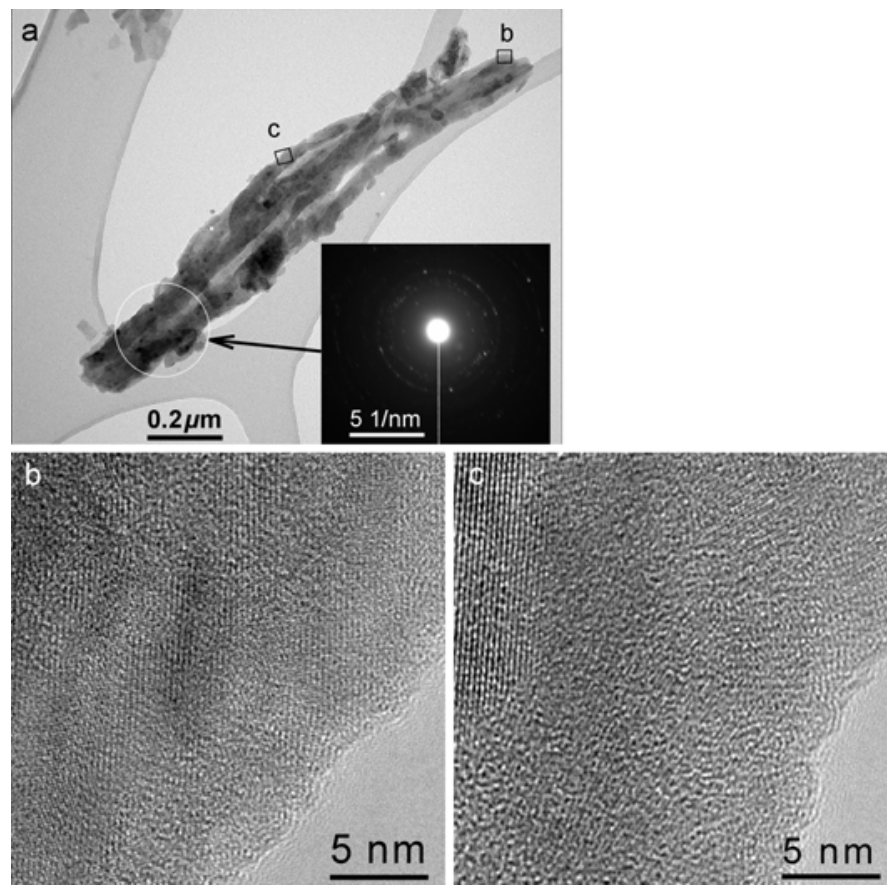

A Haake Rheocord 90 Torque Mixer was used for the mechanical mixing of the PU and attapulgite clay at $200{ }^{\circ} \mathrm{C}$ and the SMP nanocomposite sheets (about $3 \mathrm{~mm}$ thickness, with nanoclay contents of 10, 20 and 30 wt.\%) were prepared by a hot-pressing method [21]. TEM was used to study the microstructure of the nanocomposites. Nanoindentation was performed using a TriboIndentor, (Hysitron Inc., USA), with a Berkovich diamond tip. Load-depth curves were recorded with a peak load of $400 \mathrm{mN}$ with a loading/unloading rate of $10 \mathrm{mN} / \mathrm{s}$ and a hold time of $5 \mathrm{~s}$. For comparison, micro-hardness (Vickers) testing was also performed on the SMP and nanocomposite samples. The indentation loads were varied between 98 and $980 \mathrm{mN}$ and the indentation time was fixed at $20 \mathrm{~s}$. All indentation work was performed on three randomly selected locations on the sample with at least five effective indents for each sample. Dynamic mechanical thermal analysis (DMTA) were carried out in cantilever bending mode with a TA Instruments DMA 2980 at a frequency of $1 \mathrm{~Hz}$, a heating rate of $2{ }^{\circ} \mathrm{C} / \mathrm{min}$ and a temperature range from 25 to $100{ }^{\circ} \mathrm{C}$.

Thermo-mechanical cyclic tests, as demonstrated on Figure 2, were performed using an Instron Universal Testing Instrument (Type 5567) at a constant crosshead speed of $5 \mathrm{~mm} / \mathrm{min}$ to investigate the shape memory effect of the SMP and nanocomposites. The specimen was loaded to a strain $\left(\varepsilon_{\mathrm{m}}\right)$ at a temperature $T_{\text {high }}$ (Stage 1). Then, it was cooled to the temperature $T_{\text {low }}$ while holding the same strain $\varepsilon_{\mathrm{m}}$ (Stage 2). After $5 \mathrm{~min}$ at the temperature $T_{\text {low }}$, the load on the specimen was released (Stage 3 ), and the unloaded specimen was heated from $T_{\text {low }}$ to $T_{\text {high }}$ in 5 min (Stage 4); $\varepsilon_{\mathrm{e}}$ is the strain after unloading, $\varepsilon_{\mathrm{p}}$ is the permanent strain. The basic conditions and definitions in a cycle were as follows: $\varepsilon_{\mathrm{m}}=25 \%$; $T_{\text {high }}=60^{\circ} \mathrm{C} ; T_{\text {low }}=20^{\circ} \mathrm{C}$. 
Figure 2. 3-D schematic drawings of cyclic tensile testing, There are four steps in each cycle: (1) stretching to $\varepsilon_{\mathrm{m}}$ at $T_{\text {high }}$; (2) gooling to $T_{\text {low }}$ with holding strain; (3) unloading and keeping shape at $T_{\text {low }} ;(4)$ heating up to $T_{\text {high }}$, then starting the next cycle.

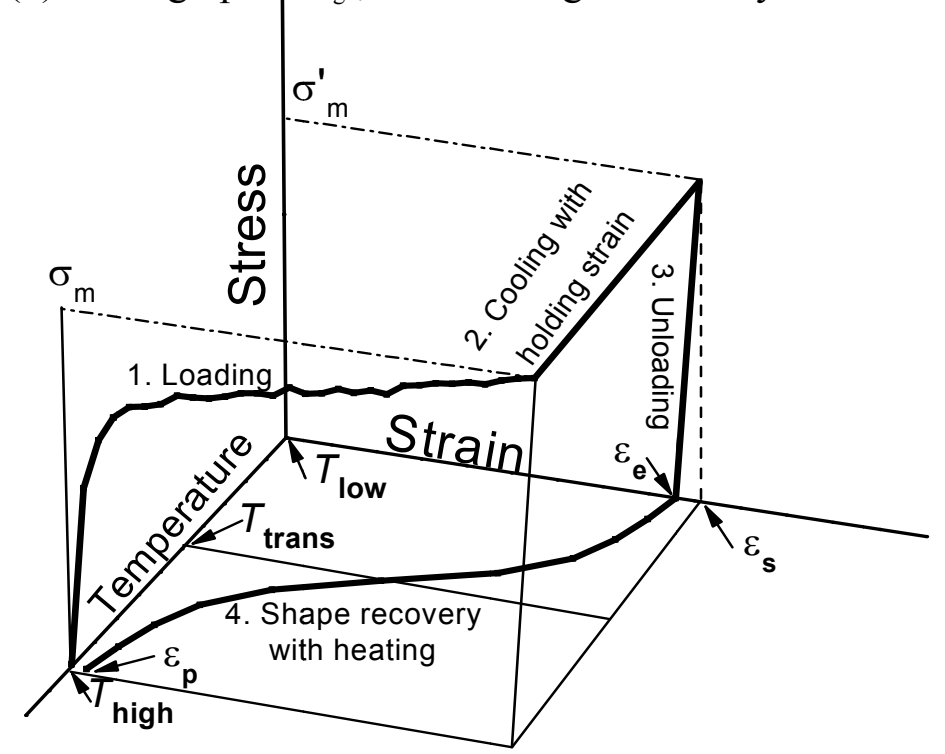

\section{Results and Discussion}

TEM analysis of the nanocomposites shown in Figure 3(a) indicates that the nanoclay rods are randomly distributed inside the PU matrix, as illustrated schematically in Figure 3(b). However, the bundles of nano-clay network can still be observed and a more effective dispersion method of nano-clay powder in polymer matrix for a better organic/inorganic interface might be obtained by purifying the clay with organic reagent, or chemical surface grafting.

Figure 3. (a) TEM observation showing the distribution of nano-clay and clay bundle structures in $30 \mathrm{wt} . \%$ clay/PU composites; (b) illustration of nano-clay embedded inside PU matrix.
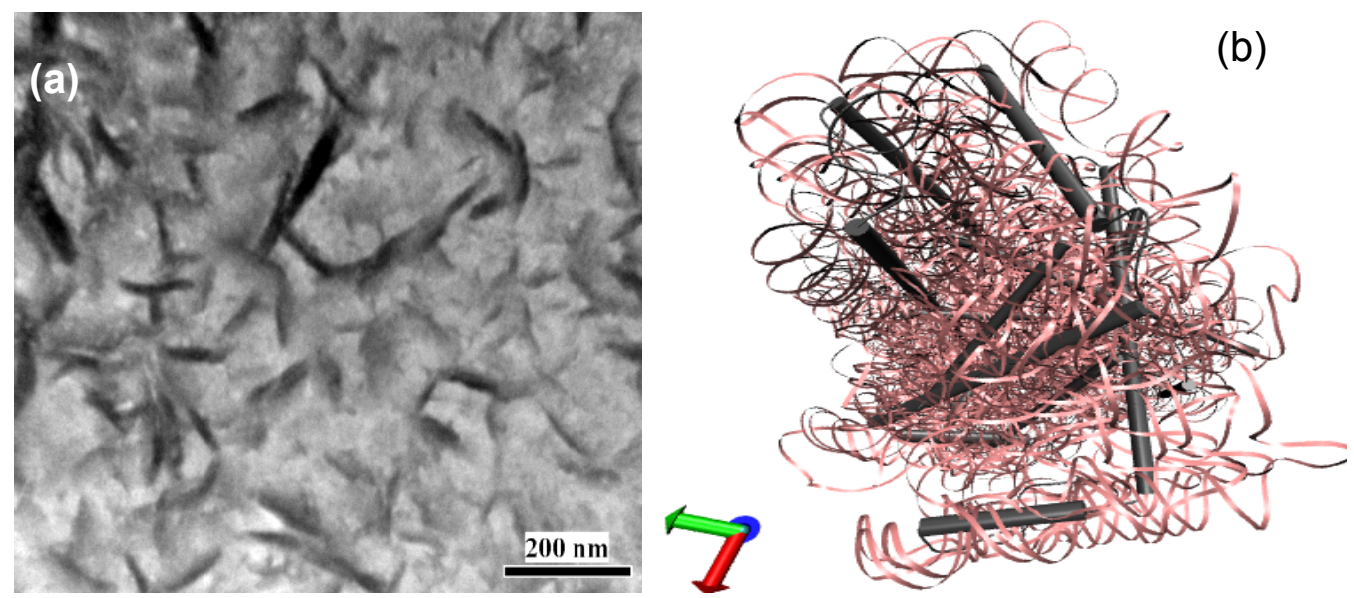
The loading-unloading curves for the nano-indentation of PU and its nanocomposites are shown in Figure 4(a). The indentation depth under a fixed load $(400 \mathrm{mN})$ gradually decreases with increasing clay content, indicating an increase in the resistance to plastic deformation. A reduction of the strain recovery during unloading period with the addition of nano filler is also observed, because incorporating the nano-fillers in the microstructure hampers the movement of molecular chains during deformation. Figure 4(b) illustrates the hardness profiles for the PU sample and its nanocomposites as a function of indentation depth. At a very shallow indentation depth, the hardness is very high because of the indentation size effect (ISE) [22-24]. Several explanations have been used to explain the origin of the ISE, including limitations in experimental conditions (low resolution of the objective lens, work hardening or softening generated during the surface preparation, intrinsic structural factors of the material such as work hardening during indentation, friction at the interface, indentation elastic recovery, and grain size effect) [21-23]. In this study, the LSE is probably from work hardening of the polymer and nanocomposites. The averaged hardness value increases by about $90 \%$, from $89 \mathrm{MPa}$ to $166 \mathrm{MPa}$ when the filler content is increased from 0 to $30 \mathrm{wt} . \%$. The nanoindentation results also show a slight increase in improvement in yield stress with increasing filler content. Figure 4(c,d) shows the surface morphology of the indentation marks for the pure PU and nanocomposite (with 30 wt.\% clay) from the nano-indentation test. For the pure PU, a pile-up of materials can be observed indicating its soft nature, whereas, for the $30 \mathrm{wt} . \%$ nanoclay composite, the pile-up is severely restrained because of the increase in the mechanical strength of the nanocomposites.

Figure 4. (a) Typical nanoindentation results of samples; (b) hardness versus indentation depth derived from nanoindentation tests; (c) AFM images for pile-up of materials for the pure PU sample; (d) AFM images of indentation mark on $30 \mathrm{wt} . \%$ clay/PU.
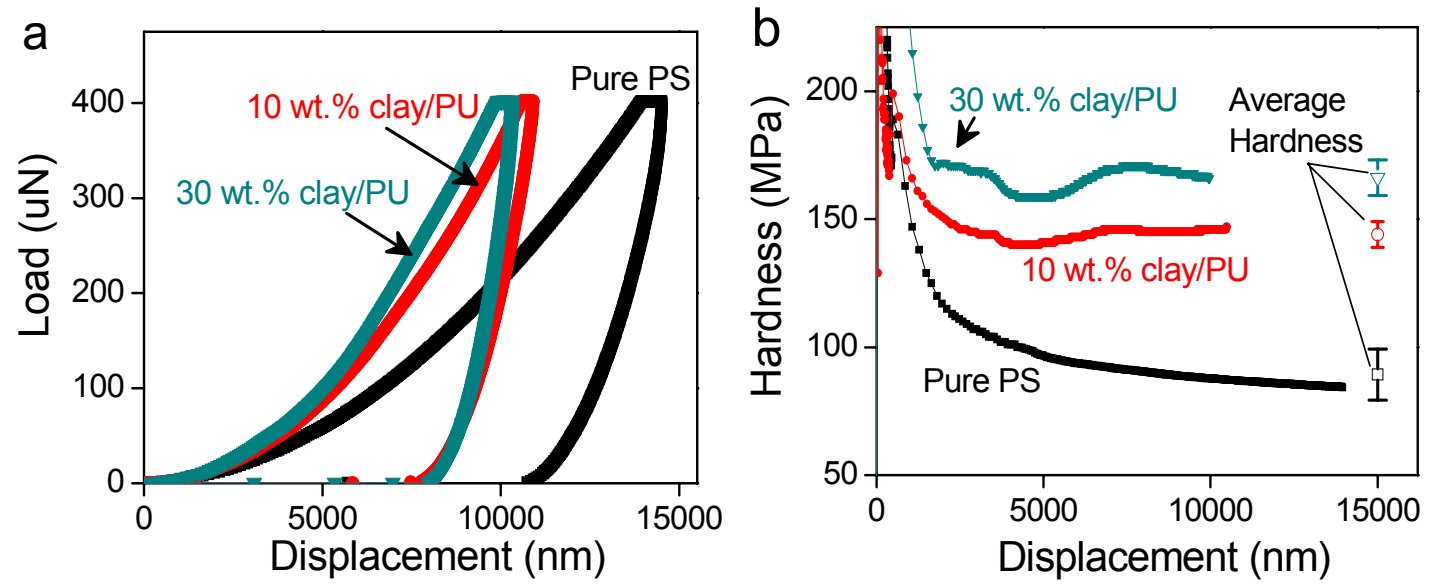

C
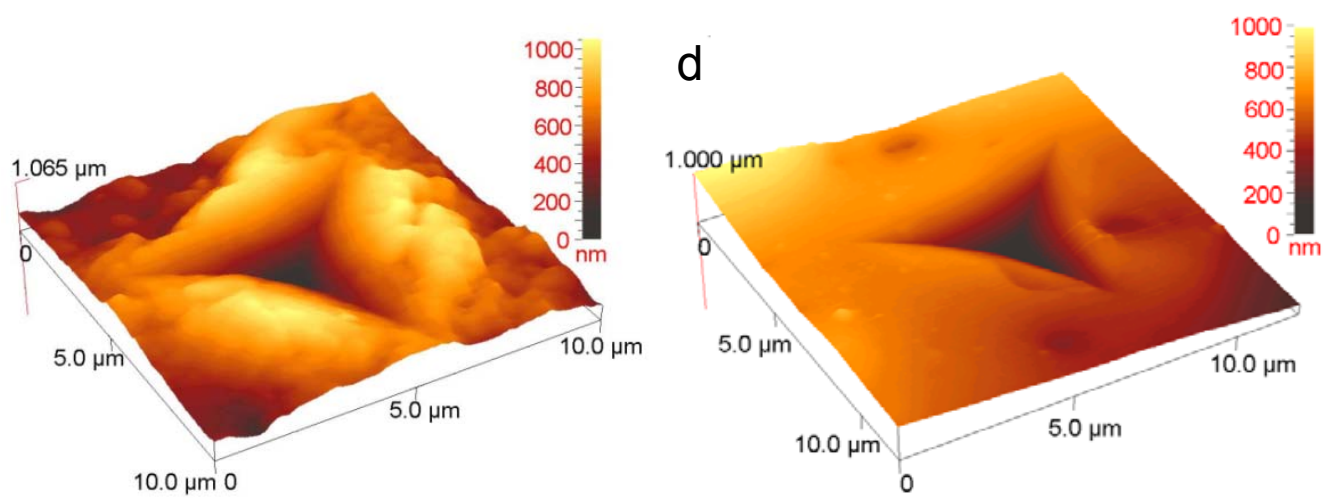
A comparison of hardness values from the nanoindentation and Vicker's microindentation are presented in Figure 5. The two measurements are comparable and show a very similar trend of relation between the hardness and the content of clay fibres in the nanocomposites. This result is useful for industrial applications as it indicates that a Vickers micro-indentation test can be used equally with nanoindentation.

Figure 5. Hardness comparison between results from nanoindentation and Vickers hardness tests.

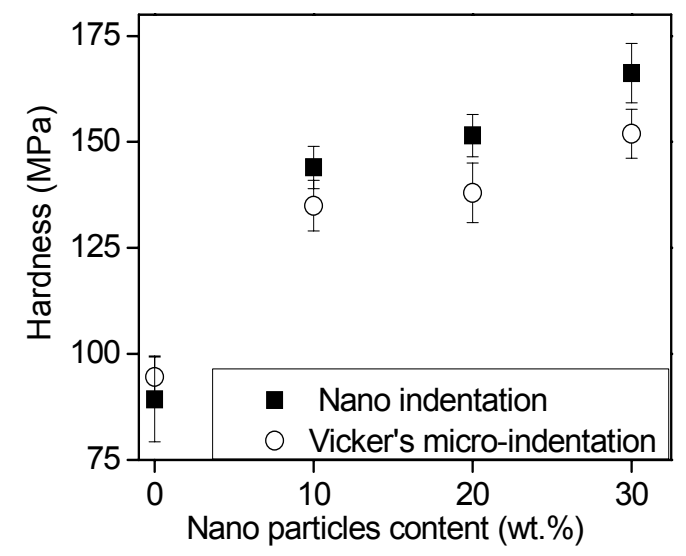

Figure 6(a) shows the storage moduli $\left(E^{\prime}\right)$ for the composites with different clay contents from DMTA tests. The storage modulus has a maximum value for the SMP nanocomposite with 30 wt.\% clay, indicating that the stiffness of $30 \mathrm{wt} . \%$ clay/PS nanocomposite is the highest among all the tested samples. A sharp drop in modulus is observed above $T_{\mathrm{g}}$ within a narrow temperature range due to the softening effect of the polymer nanocomposite, which was frequently reported [25]. The tan $\delta$ curves shown in Figure 6(b) reveal that the transition temperatures of the nanocomposites increase with clay content. The nanocomposite with $30 \mathrm{wt}$ \% clay also shows the highest $\tan \delta$ value, which reveals its best energy absorption capacity among these samples [26]. It was reported that the damping effect of the polymer depends strongly on the content of hard segment, crystallization of the soft segment and cross-linking rate $[27,28]$. In this study, the best damping effect was achieved for the nanocomposites with $30 \mathrm{wt} . \%$ clay, because of the significant increase in the content of hard segments.

Figure 6. DMTA characterization on $T_{\text {trans }}$ of nanoclay based SMP composites (a) Storage modulus versus temperature curves; (b) Tan $\delta$ versus temperature results.
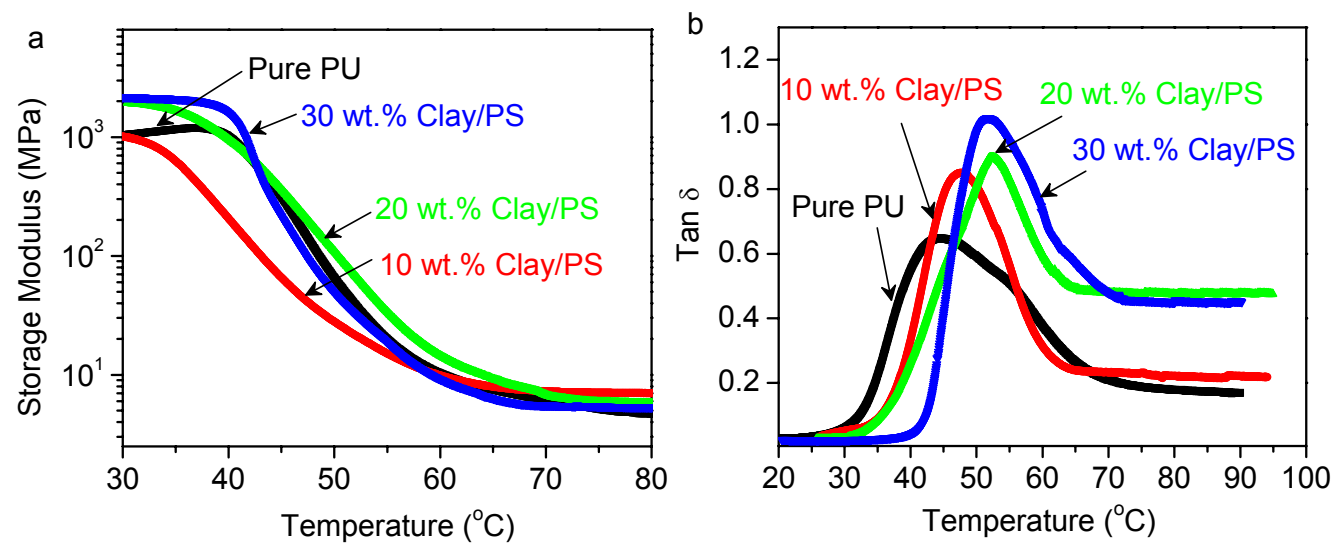
Figure 7 shows the thermal-mechanical cyclic test of the $30 \mathrm{wt} . \%$ clay composite. A good shape recovery was observed: the shape recovery rate is $99.2 \%$ in the first tensile cycle and $97 \%$ in the second round. The maximum stress decreased by $8 \%$ probably because some defects were generated and creep occurred during continuous loading at an air temperature of $60{ }^{\circ} \mathrm{C}$.

In order to show the shape memory effect, thin beams of pure PU and $30 \mathrm{wt} . \%$ clay/PS composites, with a cross section area of $2 \times 2 \mathrm{~mm}^{2}$, were bent after heating to $80^{\circ} \mathrm{C}$, and the shape held fixed during cooling to room temperature $\left(20^{\circ} \mathrm{C}\right)$. The shape recovery was demonstrated on a hotplate with a surface temperature of $80{ }^{\circ} \mathrm{C}$. The pure PU sample exhibited a prompt response, recovering to its original shape within $30 \mathrm{~s}$ (see Figure 8(c)). The nanocomposite beam with $30 \mathrm{wt} \%$ clay also showed a full shape memory recovery with $60 \mathrm{~s}$ (see Figure $8(\mathrm{~d})$ ). The slow recovery of the nanocomposite sample is attributed to the incorporation of nano-fillers that hamper the movement of molecular chains, so that the shape memory effect was slightly delayed.

Figure 7. Typical thermal cyclic tensile results of 30 wt.\% clay SMP nanocomposite.

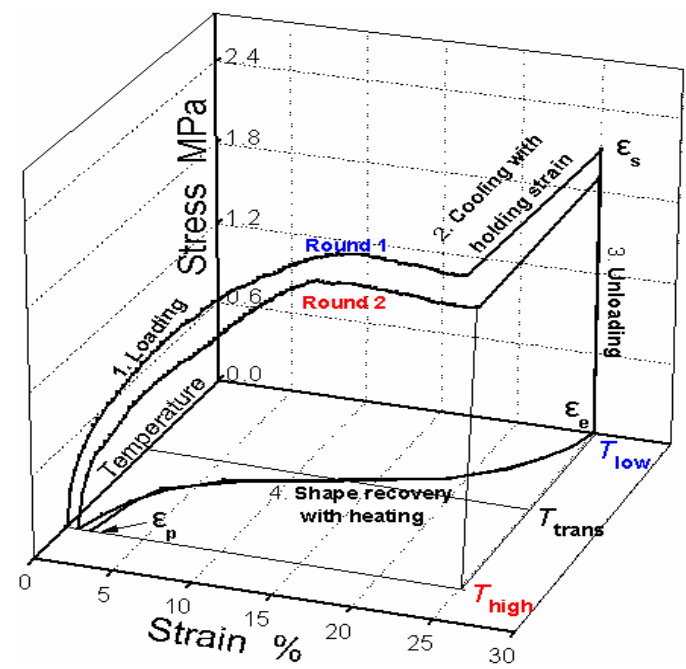

Figure 8. Recovery of shape memory samples heated on a hotplate with a surface temperature of $80^{\circ} \mathrm{C}$.

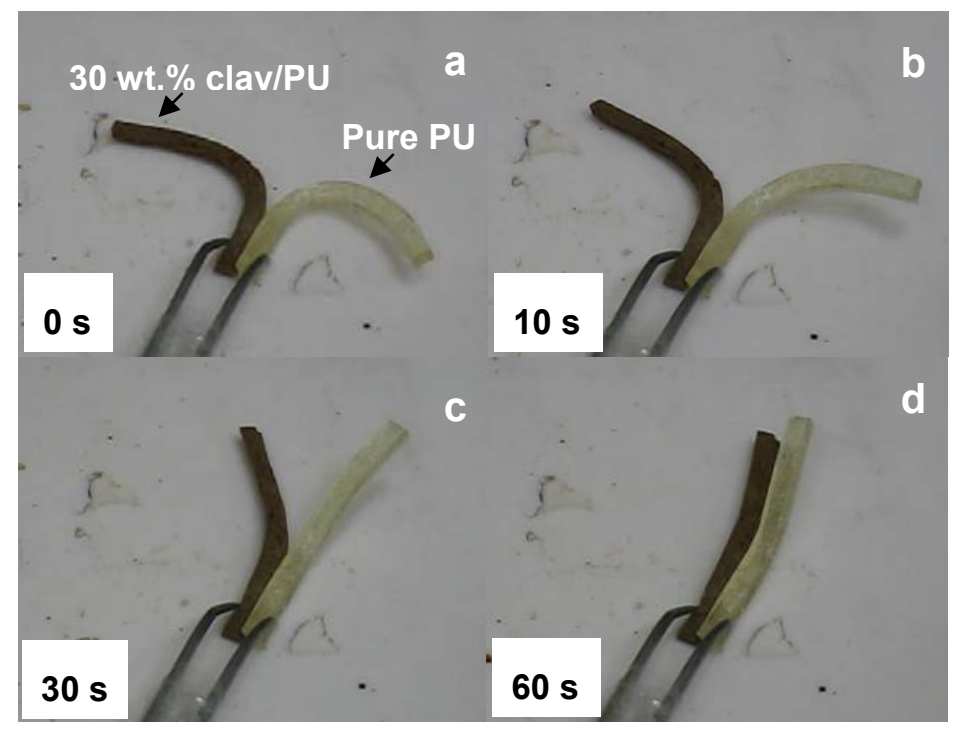




\section{Conclusions}

Shape memory nanocomposites of polyurethane (PU)-clay were fabricated by mechanical mixing of PU and nano-clay powder. Nanoindentation results showed that the averaged hardness value increases by about $90 \%$, from $89 \mathrm{MPa}$ to $166 \mathrm{MPa}$ when the content of nanoclay filler reaches $30 \mathrm{wt} . \%$. DMTA also showed the improvement in the thermo-mechanical properties of the nanocomposites by adding the nano clay fillers. Good shape memory effect was observed in the nano-composites: nearly $97 \%$ recovery was obtained after two cyclic tensile tests.

\section{Acknowledgements}

The authors acknowledge the financial supports of the Royal Academy of Engineering Research Exchanges with China and India Awards, Royal Society-Research Grant, Royal Society of Edinburgh, Carnegie Trust Funding, and China-Scotland Higher Education Partnership. Attapulgite clay was kindly provided by G. H. Pan at Southeast University, PR China. W.M. Huang would like to thank the financial support from A*STAR(SERC:0921370016), Singapore.

\section{References}

1. Kim, B.K.; Lee, S.Y.; Xu, M. Polyurethanes having shape memory effects. Polymer 1996, 37, 5781-5793.

2. Baer, G.; Wilson, T.S.; Matthews, D.L.; Maitland, D.J. Shape-memory behavior of thermally stimulated polyurethane for medical applications. J. Appl. Polym. Sci. 2006, 103, 3882-3892.

3. Mohr, R.; Kratz, K.; Weigel, T.; Lucka-Gabor, M.; Moneke, M.; Lendlein, A. Initiation of shape-memory effect by inductive heating of magnetic nanoparticles in thermoplastic polymers. Proc. Natl. Acad. Sci. USA 2006, 103, 3540-3545.

4. Huang, W.M.; Yang, B.; An, L.; Li, C.; Chan, Y.S. Water-driven programmable polyurethane shape memory polymer: Demonstration and mechanism. Appl. Phys. Lett. 2005, 86, 114105.

5. Hayashi, S.; Kondo, S.; Kapadia, P.; Ushioda, E. Room-temperaturefunctional shape-memory polymers. Plast. Eng. 1995, 51, 29-31.

6. Liang, C.; Rogers, C.A.; Malafeew, E. Investigation of shape memory polymers and their hybrid composites. J. Intell. Mater. Syst. Struct. 1997, 8, 380-386.

7. Gall, K.; Kreiner, P.; Turner, D.; Hulse, M. Shape-memory polymers for microelectromechanical systems. J. MEMS 2004, 13, 472-483.

8. Langer, R.; Tirrell, D.A. Designing materials for biology and medicine. Nature 2004, 428, 487-492.

9. Anderson, D.G.; Burdick, J.A.; Langer, R. Materials science: Smart biomaterials. Science 2004, 305, 1923-1924.

10. Balazs, A.C.; Emrick, T.; Russell, T.P. Nanoparticle polymer composites: Where two small worlds meet. Science 2006, 314, 1107-1110.

11. Utracki, L.A. Polymeric nanocomposites: Compounding and performance. J. Nanosci. Nanotechnol. 2008, 8, 1582-1596. 
12. Carrado, K.A. Synthetic organo- and polymer-clays: preparation, characterization, and materials applications. Appl. Clay Sci. 2000, 17, 1-23.

13. Hussain, F.; Hojjati, M.; Okamoto, M.; Gorga, R.E. Review article: Polymer-matrix nanocomposites, processing, manufacturing, and application: An overview. J. Comp. Mater. 2006, 40, 1511-1575.

14. Carastan, D.J.; Demarquette N.R. Polystyrene/clay nanocomposites. Int. Mater. Rev. 2007, 52, 345-380.

15. Ni, P.; Li, J.; Suo, J.S.; Li, S.B. Study on mechanical properties of polyurethane-attapulgite nanocomposites. J. Mater. Sci. 2004, 39, 4671-4673.

16. Wang, Z.Q.; Zhou, Y.M.; Sun, Y.Q. Preparation, characterization and infrared emissivity study of attapulgite@helical polyurethane composites. J. Inorg. Organmet. P. 2009, 19, 202-207.

17. Pan, H.X.; Chen, D.J. Preparation and characterization of waterborne polyurethane/attapulgite nanocomposites. Eur. Polym. J. 2007, 43, 3766-3772.

18. Bradley, W.F. The structural scheme of attapulgite. Amer. Mineral 1940, 25, 405-410.

19. Galan, E. Properties and applications of palygorskite-sepiolite clays. Clay Miner. 1996, 31, 443-453.

20. Xu, B.; Huang, W.M.; Pei, Y.T.; Chen, Z.G.; Kraft, A.; Reuben, R.; De Hosson, J.T.M.; Fu, Y.Q. Mechanical properties of attapulgite clay reinforced polyurethane shape memory nanocomposites. Eur. Polym. J. 2009, 45, 1904-1911.

21. Pan, G.H.; Huang, W.M.; Ng, Z.C.; Liu, N.; Phee, S.J. Glass transition temperature of polyurethane shape memory polymer reinforced with treated/non-treated attapulgite (playgorskite) clay in dry and wet conditions. Smart Mater. Struct. 2008, 17, 045007.

22. Manika, E.; Maniks, J. Size effects in micro- and nanoscale indentation. Acta Mater. 2006, 54, 2049-2056.

23. Gao Y.X.; Fan, H. A micro-mechanism based analysis for size-dependent indentation hardness. J. Mater. Sci. 2002, 20, 4493-4498.

24. Iost, A.; Bigot, R. Indentation size effect: Reality or artefact? J. Mater. Sci. 1996, 13, 3573-3577.

25. Kim, B.K.; Shin, Y.J.; Cho, S.M.; Jeong, H.M. Shape-memory behavior of segmented polyurethanes with an amorphous reversible phase: The effect of block length and content. J. Polym. Sci. B: Polym. Phys. 2000, 38, 2652-2657.

26. Lee, B.S.; Chun, B.C.; Chung, Y.C.; Sul, K.I.; Chos, J.W. Structure and thermomechanical properties of polyurethane block copolymers with shape memory effect. Macromolecules 2001, 34, 6431-6437.

27. Takahashi, T.; Hayashi, N.; Hayashi, S. Structure and properties of shape-emory polyurethane block copolymers. J. Appli. Polym. Sci. 1996, 60, 1061-1069.

28. Pissis, P.; Apekis, L.; Christtodoulides, C.; Niaounakis, M.; Kyritsis, A.; Nedbal, J. Water effects in polyurethane block copolymers Kyritsis, A.; Nedbal, J. J. Polym. Sci. B: Polym. Phys. 1996, 34, $1529-1539$.

(C) 2010 by the authors; licensee MDPI, Basel, Switzerland. This article is an open-access article distributed under the terms and conditions of the Creative Commons Attribution license (http://creativecommons.org/licenses/by/3.0/). 